\title{
Evaluation of forensic chemical method performances by phase tagging
}

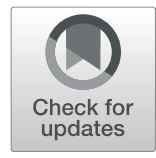

Kar-Weng Chan

Dear Editor,

Forensic chemistry is largely governed by the theories, principles, and good laboratory practices (GLPs) of analytical chemistry. Only when these aspects are closely observed and adhered, the laboratory result can then serve as a meaningful evidence to assist the enforcement body and victim to seek justice. The endgame of forensic analysis is to ensure the laboratory findings can provide a final conclusion stating whether a crime has taken place (i.e., is a drug present in the seized bulk?). But prior to granting assurance to this final conclusion, reliability of the way of analysis will be a burning question for forensic chemists to affirm upfront. So the technical capacity and capability (e.g., competency) of a forensic laboratory that factors in performances of methods of analytical chemistry must be zoomed in on. To this end, there is a need to come up with a general guideline to quantifying the capability of a forensic chemical method by giving it a phase/stage. The guideline will streamline the users' knowledge in assessing the fitness of a method under discussion and setting analytical expectations in a more realistic way.

In the name of validity, a laboratory's capability must be understood/accepted before it can ferret out scientific findings to formulate conclusions for all criminal cases. This is implied in the quote that echoes, "accurate laboratory test results depend on staff being competent in performing the range of procedures that occur throughout the entire examination process" (World Health Organization 2015). Competency of a laboratory that performs a given test is the summed effect of the performance of the personnel, instrument/tools, and method involved in the testing. Staff's competence is endorsed by assessing his/her ability in following documented procedures to produce or reproduce a set of

Correspondence: chankarweng@yahoo.com; chankw@kimia.gov.my Research and Instrumentation Section, Department of Chemistry Malaysia, Ministry of Science, Technology \& Innovation (MOSTI), Petaling Jaya, Malaysia laboratory findings within the laboratory's known performance band (United Nations Industrial Development Organization 2009). They must have received adequate training and achieved competence in the method before commencing actual casework (United Nations Office on Drugs and Crime 2009). An instrument's performance is evaluated by ensuring that the standard hardware and software setup/settings are able to produce expected results using specific test kits (i.e., n-alkanes to check gas chromatograph (GC), polystyrene film to verify infrared measurement). A method's performance, on the other hand, is checked by examining if the instrument can meet the acceptance criteria for all performance characteristics (e.g., precision and recovery) mandated by the laboratory.

Much similar to clinical testing before a new drug is marketed, four phases can be employed to describe the amount of effort invested into understanding an analytical method's performance. Certain methods may have little data to prove its fitness for the intended purpose because it is not routinely used. On the contrary, certain methods are extensively used, and a large set of data are available to portray its behavior. Table 1 summarizes four phases, which may be useful for forensic chemists to quantify the competency of an instrumental method designed for a target analysis. Based upon the four phases, all users of interest will better understand the capability of a method in question because the phases provide a clear tag to the method based on how thoroughly the method has been investigated and understood.

These phases can be narrowly used to represent the stages in method evaluation. Oftentimes, a method may have been subjected to optimization at the pilot stage (phase I). Such key performance characteristics as precision and bias are not well studied. The aim of this pilot stage is to check the feasibility of a questioned method in performing an intended analysis. Therefore, a small number of samples $(n<10)$ are required to guarantee its 
Table 1 Four phases for a forensic chemical method to describe its performance

\begin{tabular}{|c|c|c|}
\hline Phase & Stage & Description and scope \\
\hline I & Pilot & $\begin{array}{l}\text { The method has been pilot tested using a small number of samples }(n<10) \text {. The findings are indicative of the suitability } \\
\text { of the method for the intended purpose. At this stage, the method has been optimized but no proper data are in place } \\
\text { to support its fitness. Some level of selectivity is usually achieved. }\end{array}$ \\
\hline$\|$ & Validated & $\begin{array}{l}\text { The method has been appropriately tested for its fitness in terms of selectivity, precision, linearity, accuracy, sensitivity, } \\
\text { ruggedness/robustness, etc. depending on its purpose. The obtained findings are able to meet the minimum acceptance } \\
\text { criteria set by the laboratory or by the scientific community at large. }\end{array}$ \\
\hline Illa & Proven & $\begin{array}{l}\text { The validated method is further tested using contrived samples or a small set of real samples }(n<100) \text { to test its performance. } \\
\text { A high level of confidence is observed in the findings. }\end{array}$ \\
\hline IIllb & In-use & $\begin{array}{l}\text { The validated method is further verified using a large set of real samples }(n>100) \text { on a routine basis to test its practicality in } \\
\text { terms of interference and consistency. }\end{array}$ \\
\hline IV & Idyllic & The method in use is employed in proficiency testing where the results are within the intended $z$-score. \\
\hline
\end{tabular}

practicality at a glance. The method is dismissed or reoptimized if it does not give promising outcomes (e.g., bad consistency). Somehow, half-optimized methods at the pilot stage may be adopted by a routine laboratory to do screening. In such a case, the method will be tagged 'Phase 1' and this will convey the level of reliability of the obtained results as preliminary findings to the user.

When a method has reached the validated stage (phase II), all relevant performance characteristics (ISO 2005) ought to have been assessed and possible errors defined. All forensic chemical methods must go through phase II before it can be employed for caseworks or considered for accreditation. Through routine practice, the method is subsequently subjected to real sample analysis in phase III by retesting its practicality to a larger extent. Not all methods can undergo phase IIIb if the method is not practiced for a sufficiently long period of time especially when the target analyte becomes fast irrelevant. With the validated method in place, the performance is deemed trustable and results proven (phase IIIa) if a small set of real samples $(n<100)$ exhibits good precision and stability. It is better described as "in-use" (phase IIIb) if quality control samples, together with case samples, do not raise doubts. The minimum number of samples $=100$ for phase IIIb is sufficient for the laboratory to statistically gain a good overview of the performance for the method. An idyllic method (phase IV) is obtained when it has been routinely used for a long period of time, throughout which proficiency testing results display good outcomes.

Under most circumstances, modifications to an in-use or idyllic method are necessary to cater for the evolution of sample matrices. This also occurs when the phase III method does not seem to give expected results (i.e., false negatives raise doubts especially when the target method in question does not seem to give congruent results with a second method). Hence, the method is modified and must go through verification to earn its new label as a validated method (phase II) and be substantiated its practicality by actively using it on a routine basis to get through phase III and IV. After all, the way how the entire phase/stage labeling should be executed relies on the documented decision of the quality management.

In the forensic context, it is recommended to label a method under discussion with a suitable phase or stage so that the forensic community can impose the same impression and expectation on the method. For instance, a phase IV method (or idyllic method) is deemed superior and well established in comparison with a phase IIIa method (or proven method) as far as reliability is concerned. If a method is tagged with an appropriate phase or stage, this will help chemists reach a consensus on what is expected of the method.

\section{Abbreviations \\ GLP: Good laboratory practice; GC: Gas chromatograph}

Acknowledgements

Not applicable

Adherence to national and international regulations

Not applicable.

Author's contributions

Critically thought through the topic. The author(s) read and approved the final manuscript.

\section{Author's information}

KW Chan holds a PhD majoring in analytical chemistry with a focus on drug analysis and drug profiling. He had been a practicing forensic chemist in narcotic enforcement laboratory (2005-2016). Currently, he works as a forensic researcher, a position that allows him to actively develop instrumental methods for the testing of illicit substances for narcotic and toxicological cases.

Funding

Not applicable.

Availability of data and materials

Sample data for the four phases of a method can be obtained from the author.

Ethics approval and consent to participate

Not applicable.

Consent for publication

Not applicable. 


\section{Competing interests}

The author declares that he has no competing interests.

Received: 30 July 2019 Accepted: 11 August 2020

Published online: 10 September 2020

\section{References}

ISO (2005). ISO/IEC 17025 General requirements for the competence of testing and calibration laboratories. Switzerland.

United Nations Industrial Development Organization (2009). Complying with ISO17025: a practical guidebook for meeting the requirements of laboratory accreditation schemes based on ISO 17025:2005 or equivalent national standards. Vienna, Austria.

United Nations Office on Drugs and Crime (2009). Guidance for the validation of analytical methodology and calibration of equipment used for testing of illicit drugs in seized materials and biological specimens. Vienna, Austria. World Health Organization (2015). Laboratory quality stepwise implementation tool. Retrieved July 25, 2019 from https://extranet.who.int/lqsi/content/ perform-staff-competency-assessments

\section{Publisher's Note}

Springer Nature remains neutral with regard to jurisdictional claims in published maps and institutional affiliations.

\section{Submit your manuscript to a SpringerOpen ${ }^{\circ}$ journal and benefit from:}

- Convenient online submission

- Rigorous peer review

- Open access: articles freely available online

- High visibility within the field

- Retaining the copyright to your article 